\title{
"Impact of commodities and global stock prices on the idiosyncratic risk of Bitcoin during the COVID-19 pandemic"
}

\begin{tabular}{|c|c|}
\hline AUTHORS & $\begin{array}{l}\text { Edgardo Cayón Fallon (iD) } \\
\mathbb{R} \\
\text { Julio Sarmiento (iD) } \\
\mathbb{R}\end{array}$ \\
\hline ARTICLE INFO & $\begin{array}{l}\text { Edgardo Cayón Fallon and Julio Sarmiento (2021). Impact of commodities and } \\
\text { global stock prices on the idiosyncratic risk of Bitcoin during the COVID-19 } \\
\text { pandemic. Investment Management and Financial Innovations, 18(4), 213-222. } \\
\text { doi:10.21511/imfi.18(4).2021.19 }\end{array}$ \\
\hline DOI & http://dx.doi.org/10.21511/imfi.18(4).2021.19 \\
\hline RELEASED ON & Wednesday, 24 November 2021 \\
\hline RECEIVED ON & Wednesday, 13 October 2021 \\
\hline ACCEPTED ON & Tuesday, 16 November 2021 \\
\hline LICENSE & $\begin{array}{l}(c)) \text { EY } \\
\text { This work is licensed under a Creative Commons Attribution } 4.0 \text { International } \\
\text { License }\end{array}$ \\
\hline JOURNAL & "Investment Management and Financial Innovations" \\
\hline ISSN PRINT & $1810-4967$ \\
\hline ISSN ONLINE & $1812-9358$ \\
\hline PUBLISHER & LLC "Consulting Publishing Company "Business Perspectives" \\
\hline FOUNDER & LLC "Consulting Publishing Company "Business Perspectives" \\
\hline
\end{tabular}

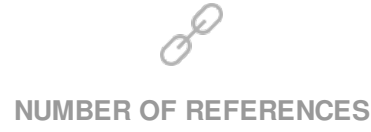

37

\section{NUMBER OF FIGURES}

3
NUMBER OF TABLES

4

(C) The author(s) 2021. This publication is an open access article. 


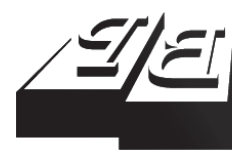

BUSINESS PERSPECTIVES

(O)

LLC "CPC "Business Perspectives"

Hryhorii Skovoroda lane, 10,

Sumy, 40022, Ukraine

www.businessperspectives.org
Received on: $13^{\text {th }}$ of October, 2021 Accepted on: $16^{\text {th }}$ of November, 2021 Published on: $24^{\text {th }}$ of November, 2021

(c) Edgardo Cayón Fallon, Julio Sarmiento, 2021

Edgardo Cayón Fallon, Professor of Finance, Finance Department, CESA Business School, Colombia. (Corresponding author)

Julio Sarmiento, Professor of Finance, Pontificia Universidad Javeriana, Colombia.

Edgardo Cayón Fallon (Colombia), Julio Sarmiento (Colombia)

IMPACT OF COMMODITIES

AND GLOBAL STOCK PRICES ON THE IDIOSYNCRATIC RISK OF BITCOIN DURING THE COVID-19 PANDEMIC

\begin{abstract}
In times of exogenous systemic shocks, such as the COVID-19 pandemic, it is important to identify hedge or safe haven assets. Therefore, this paper analyzes changes in the idiosyncratic risk of Bitcoin in a portfolio of commodities and global stocks. For this purpose, the M-GARCH model employed considers the interdependence among all the portfolio assets by using a time-varying asset pricing framework. This framework measures the impact of commodities and global stock prices as sources of systemic risk for Bitcoin returns before and after the COVID-19 pandemic. The evidence suggests that during the COVID-19 pandemic, the effects of changes in commodities and global prices on the idiosyncratic risk of Bitcoin were statistically significant. The idiosyncratic risk of Bitcoin measured as a percentage of total variance not accounted for by the proposed model rose from $86.06 \%$ to $95.05 \%$ during the pandemic. These results are in line with previous studies regarding the properties of Bitcoin as a hedge or safe haven asset for a portfolio composed of commodities and global stocks.
\end{abstract}

\section{Keywords}

JEL Classification

\section{INTRODUCTION}

It is no secret that cryptocurrencies, such as Bitcoin, represent a series of opportunities and enigmas regarding what type of asset class they resemble or if, indeed, they constitute a new asset class. For example, Graf (2014) points out that academicians and practitioners are still arguing about how to classify Bitcoin: as a commodity, intangible asset, money, miscellaneous form, or private property. Graf (2014) makes a convincing argument that Bitcoin is a form of "pure" commodity money that, thanks to its intangible nature, takes the same role as commodity-backed fiat monies that have existed through history. Baldan and Zen (2020) and Hayes (2019) reinforce this argument by arguing that Bitcoin can be treated as a "virtual commodity" because it can be produced (Bitcoin miners) and can be acquired by individuals in different marketplaces, which is very similar to the process in which physical commodities are produced and traded. However, there is evidence that, even though Bitcoin theoretically shares similar characteristics with the commodities market, it behaves as a unique asset class in its own right. According to CoinMarketCap (n.d.), more than $40 \%$ of the total USD 1.9 trillion cryptocurrency market capitalization is represented by Bitcoin which has become a new kind of financial asset actively sought by investors. Additionally, the trading volume increased during the COVID-19 pandemic contrary to expectation even to the point that there is suspicion of a possible price bubble (Guegan \& Frunza, 2020). Also, during the COVID-19 pandemic, the Bitcoin 
has seen its value increase while other traditional financial assets and commonly traded commodities have seen their value plummet. Due to its unique characteristics, it is important in an asset pricing context, to see if indeed common global systemic factors can explain the variance in Bitcoin prices during normal market conditions and if the effects on variance remain constant in times of exogenous systemic shocks such as the COVID-19 pandemic. Therefore the purpose of the study is to test the properties of Bitcoin during the before mentioned periods and to test if indeed the Bitcoin exhibited the characteristics of a safe haven asset during the COVID-19 pandemic.

\section{LITERATURE REVIEW}

Bouri et al. (2017) argued that Bitcoin can act as a diversifier for a portfolio of common asset classes, such as commodities and global stocks. Accordingly, the definitions suggested by Baur and Lucey (2010) are used where a hedge asset is defined as an asset with a negative correlation with the rest of the portfolio, a diversifier as an asset with a positive correlation that has a relationship to the systemic risk of the portfolio, and finally, a safe haven is an asset that is uncorrelated or negatively correlated with the portfolio in times of increasing market volatility or systemic risk. Shahzad et al. (2019) decided to test the hypothesis of a "weak" versus "strong" safe haven definition based on the predictability of the stock market based on the previous variations of Bitcoin in extreme market conditions. If indeed, Bitcoin is a "strong" safe haven asset, negative extreme stock index returns should be followed by positive Bitcoin returns. Conversely, a "weak" safe haven asset is where there is no evidence of predictability between the assets in extreme market conditions. It was found that, in most periods of extreme market conditions under analysis, Bitcoin would fall under the "weak" safe haven asset classification. On the empirical side, and different periods, the evidence suggests that Bitcoin can act as a diversifier under time-varying conditions (Bakry et al., 2021; Carpenter, 2016; Eisl et al., 2015). On a different setting, and using a portfolio composed of investment-grade bonds and global industry stock, Akhtaruzzaman et al. (2020) found that Bitcoin acted as a diversifier for these kinds of assets. For the majority of common financial assets, there was a contagion effect during the COVID-19 pandemic (Akhtaruzzaman et al., 2021). On the other hand, Ghorbel and Jeribi (2021b) found that in the case of energy markets (oil and gas) Bitcoin cannot be considered a diversifier. During the COVID-19 pandemic, the linkages between oil and Bitcoin were stronger than in the pre-pandemic period (Ghorbel \& Jeribi, 2021a). However, Belhassine and Karamti (2021) using an asset pricing framework found evidence that Bitcoin showed the properties of a safe haven asset for investments in the Shanghai Stock Index.

Dyhrberg (2016) analyzed the volatility of Bitcoin under different generalized autoregressive conditional heteroskedasticity (GARCH) specifications and concluded that, for the period under scrutiny, Bitcoin shared some characteristics common to currency and gold. It was concluded that Bitcoin could be a new kind of asset class that lies between a currency and a commodity in terms of volatility. Conversely, Zhang et al. (2021) used a conditional value at risk measure to quantify the impact of volatility shocks. It was found that there is evidence of volatility spillovers from Bitcoin to other kinds of asset classes such as equities, commodities, bonds, and currencies for certain periods. Hoang et al. (2020) measured the connectedness of Bitcoin to a portfolio composed of oil and a series of agricultural commodities. The correlation of Bitcoin to the commodities was indeed low; thus, Bitcoin could act as an effective portfolio hedge to a portfolio of commodities. Salisu et al. (2019) found that, under an arbitrage price theory framework (APT), the inclusion of Bitcoin as an explanatory factor for predicting stock returns from the G7 countries improved the performance of the model and offered more explanatory power than other macroeconomic factors, except the country's interest rate. Erdas and Caglar (2018) used an asymmetric causality test to see the direction of the volatility spillovers of Bitcoin and a series of indices and commodities. It was found that there was a unidirectional effect of Bitcoin on the S\&P 500 and that a positive shock in Bitcoin leads to a negative shock in the S\&P 500 and vice versa. Using a contagion framework, Matkovskyy and Jalan (2019) found evidence that in times of 
crisis investors shifted away from Bitcoin to safer financial assets. Wang et al. (2021) argued that as the volume traded in the cryptocurrency increased, the effect of contagion to stock markets will also increase over time. There is evidence that within the different cryptocurrencies there are contagion effects in times of high price volatility and the contagion tends to originate usually from the most traded ones (Caporale et al., 2021; Ferreira \& Pereira, 2019). Schwenkler and Zheng (2020) argue that there is little evidence of contagion in the cryptocurrency market and that on the contrary positive idiosyncratic shocks are due to competition among different cryptocurrencies. This finding was corroborated by Qarni and Gulzar (2021) using a different methodology for the period comprehended between 2000 and 2017. Among the different cryptocurrencies available in the market there is a consensus that Bitcoin is the most important in terms of volume, tradability, and interdependencies with other financial markets (Ahelegbey et al., 2021; Chen et al., 2020; Tsiaras, 2021).

The negative impact of the COVID-19 pandemic on the real economy was felt at the global, regional, and local levels with devastating effects on employment and economic growth around the globe (Danylyshyn, 2020; Ozili \& Arun, 2020; Sansa, 2020). There is evidence that the COVID-19 pandemic had a negative impact on traditional financial assets in different countries in Asia (Phuong, 2021). Finally, Ozturk and Cavdar (2021) argued that, in times of an exogenous systemic shock, such as the COVID-19 pandemic, there was an increase in volatility spillovers between Bitcoin and the currency and oil markets.

\section{AIMS}

The study aims to test the hypothesis that during the COVID-19 pandemic, the effect of market shocks emanating from changes in the price of commodities and global stock prices diminished substantially during the pandemic. By using a three-factor model that allows for channels of transmissions between all the factors, namely, commodity, global stocks, and Bitcoin returns, it is possible to estimate the contribution of commodities and global stocks to the variance of the
Bitcoin idiosyncratic risk during the COVID-19 pandemic.

\section{METHODOLOGY}

The sample contains the daily closing price of the: 1) Bitcoin (BTC) index, which is the most-traded cryptocurrency; 2) The Bloomberg Commodity Index (BCOM), which is an excess return-weighted market capitalization index composed of the most-traded commodities in the futures market; and 3) The S\&P Global Broad Market Index (BMI), which includes the most representative stocks from emerging and developed markets. The data were extracted from Bloomberg and covered the period from February 10, 2016, to March 2, 2021. Summary statistics for the data are presented in Table 1.

Table 1. Descriptive statistics for Bitcoin, the Bloomberg Commodity Index, and the S\&P Global Broad Market Index

\begin{tabular}{l|c:c|c}
\hline Statistic & Bitcoin (BTC) & $\begin{array}{c}\text { Bloomberg } \\
\text { Commodity } \\
\text { Index (BCOM) }\end{array}$ & $\begin{array}{c}\text { S\&P Global } \\
\text { Broad Market } \\
\text { Index (BMI) }\end{array}$ \\
\hline Mean & 0.003802 & 0.000114 & 0.000494 \\
\hline Median & 0.003219 & 0.000536 & 0.000743 \\
\hline Maximum & 0.209837 & 0.033741 & 0.079546 \\
\hline Minimum & -0.268099 & -0.042709 & -0.100267 \\
\hline Standard & 0.046043 & 0.008090 & 0.009756 \\
deviation & -0.292648 & -0.413539 & -1.801706 \\
\hline Skewness & 7.653266 & 6.057759 & 28.02425 \\
\hdashline Kurtosis & 1,272 & 1,272 & 1,272 \\
\hline Observations & & & \\
\hline
\end{tabular}

Note: Descriptive statistics for the three indices is from February 10, 2016 to March 3, 2021.

In the case of Bitcoin and the indices' returns, the data are negatively skewed with a high kurtosis. Moreover, Bitcoin has a higher expected return, which is associated with much higher volatility than the commodity and global indices. Due to the negative skewness, there is evidence of a leverage effect, where negative returns outweigh positive returns in most cases. The statistical properties of the data were fundamental in the choice of model for estimating conditional returns to model the interdependences between the daily returns for Bitcoin and the indices to correct for problems of correlation among the variables. Counterintuitively, 


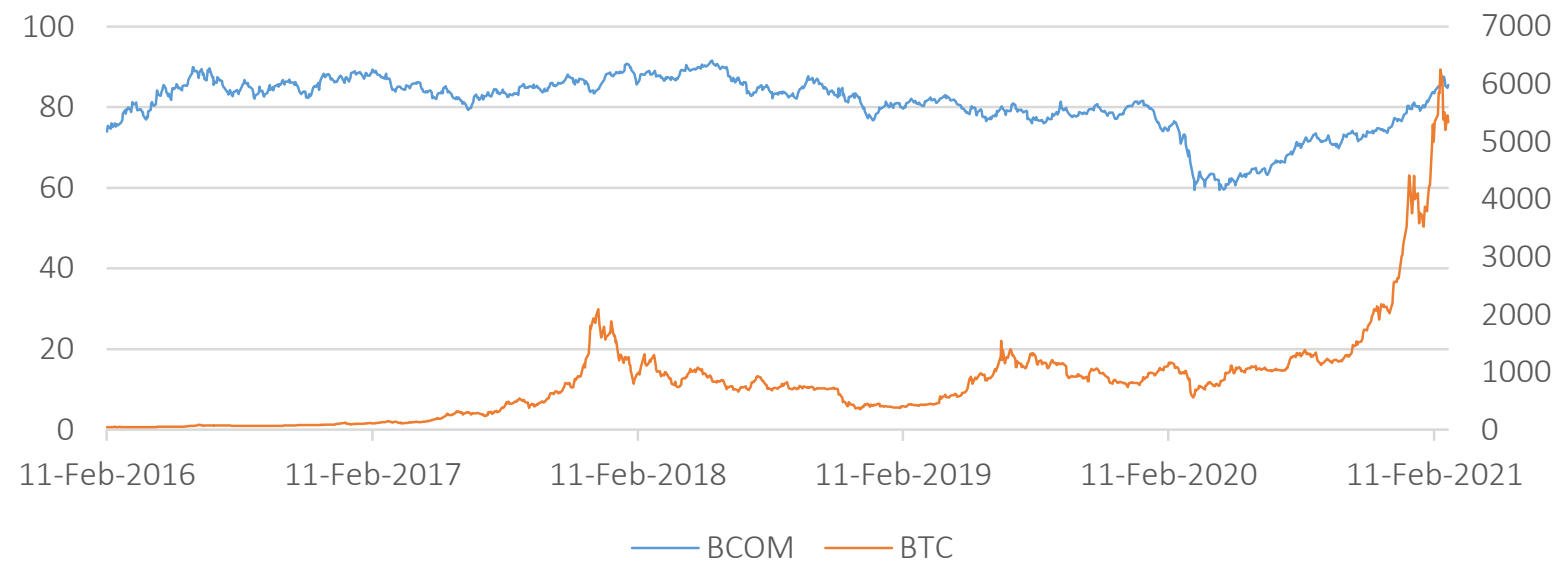

Note: The $\mathrm{Y}$-axis from the left indicates the closing daily value of the BCOM, and the Y-axis from the right indicates the closing daily value of the Bitcoin (BTC).

Figure 1. Bitcoin (BTC) and the Bloomberg Commodity Index (BCOM) from February 10, 2016 to March 2, 2021

the correlation of Bitcoin with the Bloomberg Commodity Index (BCOM) is lower than with the S\&P Global Broad Market Index (BMI). Figure 1 shows a trend at the price level for Bitcoin and the Bloomberg Commodity Index (BCOM).

At the price level, the BTC and the BCOM have a positive correlation of $12.81 \%$; the same calculation with the BMI, the correlation is $15.52 \%$. Conversely, the correlation between BMI and BCOM for the period in question is $46.11 \%$. This is a good indicator that, for the period under scrutiny, Bitcoin does not correlate heavily with traditional physical and financial assets. Figure 2 shows a trend at the price level for Bitcoin and the S\&P Global Broad Market Index (BMI).

The present study aims to model the unique component of the total risk of Bitcoin (BTC) returns. There are a series of considerations: 1) The influence of systemic shocks that derive from the commodities and global stock markets under an exogenous systemic shock, such as the COVID-19 pandemic, which is not attributable to market conditions; 2) The dynamics of the volatility between Bitcoin (BTC) and both the Bloomberg Commodity Index (BCOM) and the S\&P Global

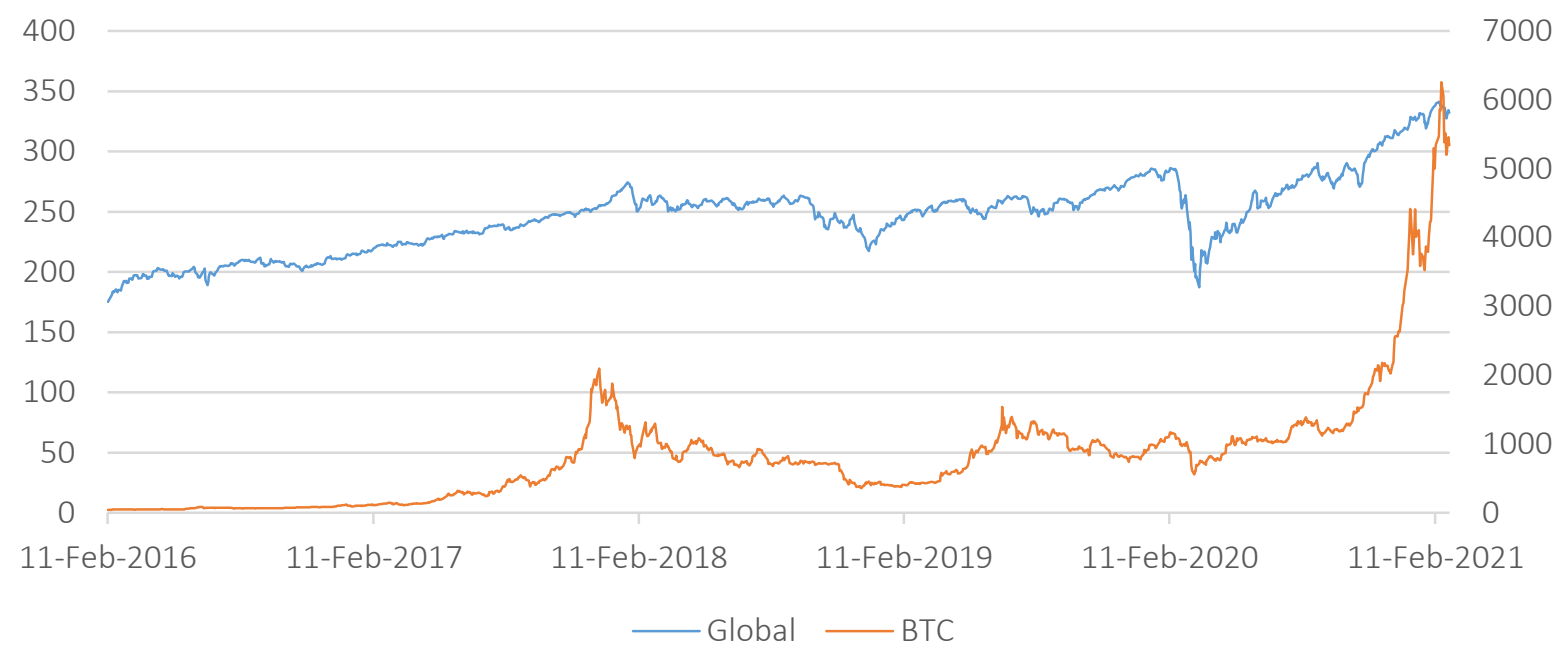

Note: The $\mathrm{Y}$-axis from the left indicates the closing daily value of the $\mathrm{BMI}$, and the $\mathrm{Y}$-axis from the right indicates the closing daily value of the Bitcoin (BTC).

Figure 2. Bitcoin (BTC) and the S\&P Global Broad Market Index (BMI) from February 10, 2016 to March 2, 2021 
Broad Market Index (BMI) and explore the changes in their dynamics due to the COVID-19 pandemic. One plausible explanation is that Bitcoin (BTC) is an asset that has certain characteristics that resemble a commodity but has some interdependence with the global markets. Therefore, it is important to model for these dynamics to have an accurate estimate of Bitcoin's unique or idiosyncratic risk under an asset pricing context. Furthermore, the COVID-19 pandemic provides a chance to observe the change of volatility dynamics between market factor shocks and to determine if Bitcoin (BTC) can act as a safe haven asset in times of uncertainty due to exogenous systemic shocks, such as the COVID-19 pandemic.

The first step is to model the time-varying volatility interaction of Bitcoin (BTC) returns between the Bloomberg Commodity Index (BCOM) and the S\&P Global Index (BMI) returns. The same procedure is used by Cayon and Thorp (2014) and Cayon and Sarmiento (2020) to model systemic conditional variance in the context of financial shocks. The first step is to allow the conditional means of the variables to follow an autoregressive moving-average (ARMA) process in the following forms (see Equation 1) to avoid the problems involved with serial correlation and to ensure that the residuals to be employed in the calculation of the multivariate GARCH (M-GARCH) represent a unique risk, as defined in an asset pricing context, of the variables in question. Therefore, the proposed ARMA processes for each variable are:

$$
\begin{aligned}
& r_{b t c, t}=\rho_{0}+\rho_{1, b t c} r_{b c o m, t}+\rho_{2, b t c} r_{b m i, t}+ \\
& +\rho_{3, b t c} r_{b t c, t-1}+\rho_{4, b t c} r_{b t c, t-2}+\varepsilon_{b t c, t}, \\
& r_{b c o m, t}=\rho_{0}+\rho_{1, b c o m} r_{b t c, t}+\rho_{2, b c o m} r_{b m i, t}+ \\
& +\rho_{3, b c o m} r_{b c o m, t-1}+\rho_{4, b c o m} r_{b c o m, t-2}+ \\
& +\theta_{5, b c o m} \varepsilon_{b c o m, t-1}+\varepsilon_{b c o m, t}, \\
& r_{b m i, t}=\rho_{0}+\rho_{1, b m i} r_{b c o m, t}+\rho_{2, b m i} r_{b t c, t}+ \\
& +\rho_{3, b m i} r_{b m i, t-1}+\rho_{4, b m i} r_{b m i, t-2}+\varepsilon_{\text {devel }, t},
\end{aligned}
$$

Where $r_{b t c, t}$ are the daily returns of the Bitcoin (BTC) for the observed period, $r_{b c o m, t}$ the daily returns of the Bloomberg Commodity Index (BCOM), and $r_{\text {devel, },}$ are the daily returns of the S\&P Global index (BMI), where in each ARMA process for $r_{b t c, t}, r_{b c o m, t}$, and $r_{b m i, t}$ which accounts for the contemporaneous interactions between each factor to account for the correlation among them. The next step is to model the conditional covariance using the residuals of the variables obtained from Equation 1 using the following specification (Equation 2) for a multivariate GARCH model (M-GARCH):

$$
\begin{aligned}
& h_{b t c_{t}}=\alpha_{0}+\alpha_{1, b t c_{t}} \varepsilon_{b t c_{t-1}}^{2}+\alpha_{2, b t t_{t}} h_{b t c_{t-1}}, \\
& h_{b c o m}=\alpha_{0}+\alpha_{1, b c o m} \varepsilon^{2}{ }_{b c o m}+1 \\
& h_{b m i_{t}}=\alpha_{0}+\alpha_{1, b m i_{t}} \varepsilon_{b m i_{t-1}}^{2}+\alpha_{2, b m i_{t}} h_{b m i_{t-1}}, \\
& h_{b t c_{t}, b c o m_{t}}=\alpha_{0}+\alpha_{1, b t c_{t}, b c o m} \varepsilon_{b t c_{t-1}} \varepsilon_{b c o m_{t-1}} \\
& ++\alpha_{2, b t c_{t}, \text { bcom }_{t}} h_{b t_{t-1}, b{ }^{\prime} m_{t-1}}, \\
& h_{b t c_{t}, b m i_{t}=} \alpha_{0}+\alpha_{1, b t c_{t}, b m i_{t}} \varepsilon_{b t c_{t-1}} \varepsilon_{b m i_{t-1}}+ \\
& +\alpha_{2, b t c_{t}, b m i_{t}} h_{b t c_{t-1}, b m i_{t-1}},
\end{aligned}
$$

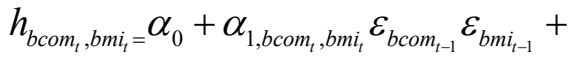

$$
\begin{aligned}
& +\alpha_{2, b o c m_{t}, b m i_{t}} h_{\text {bcom }}, b m i_{t-1} \text {, } \\
& {\left[\begin{array}{l}
\varepsilon_{b t c_{t}} \\
\varepsilon_{b c o m_{t}} \\
\varepsilon_{b m i_{t}}
\end{array}\right] \mid \Omega_{t-1} \sim} \\
& \sim N\left(\left[\begin{array}{l}
0 \\
0 \\
0
\end{array}\right],\left[\begin{array}{lll}
h_{b b c_{t}} & h_{b t c_{t}, b c o m} & h_{b t c_{t}, b m i_{t}} \\
h_{b t c_{t}, b c o m} & h_{b c o m} & h_{b m i_{t}, b c o m_{t}} \\
h_{b c_{t}, b m i_{t}} & h_{b m i_{t}, b c o m_{t}} & h_{b m i_{t}}
\end{array}\right]\right),
\end{aligned}
$$

where $h_{b t c_{t}}$ is the conditional variance of filtered returns for Bitcoin (BTC), $h_{b c o m}$ is the conditional variance of filtered returns for the Bloomberg Commodity Index (BCOM), and $h_{b m i}$ is the conditional variance of filtered returns for the S\&P Global index (BMI). In addition, $h_{b t c, b c o m}$ is the covariance between the Bitcoin (BTC) and the Bloomberg Commodity Index (BCOM), $h_{b c o m, b m i,}$ is the covariance between the Bloomberg Commodity Index (BCOM) and the S\&P Global index (BMI), and finally, $h_{b t c_{t}, b m i_{t}}$ is the covariance between the Bloomberg Commodity Index (BCOM) and the Bitcoin (BTC). Using the fitted values from the conditional variances and covariances from the M-GARCH model, the paper uses Equation 3 to compute the $\beta$ of a two-factor model in which the Bloomberg Commodity Index (BCOM) and the S\&P Global Index (BMI) explain the variance of Bitcoin (BTC): 


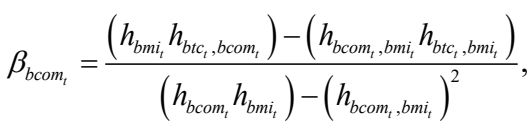

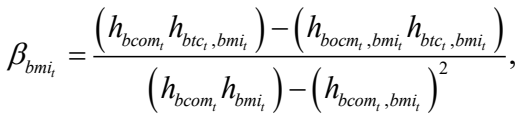

The advantage of this specification under an asset pricing context is that it allows for the discomposing the variance of Bitcoin (BTC) into systemic and idiosyncratic components in the following form:

$$
\begin{aligned}
& h_{b t c_{t}}=\beta_{b c o m_{t}}{ }^{2} h_{b c o m}+\beta_{b m i_{t}}{ }^{2} h_{b m i_{t}}+
\end{aligned}
$$

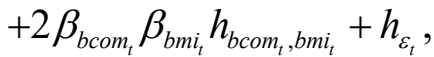

where $h_{b t c_{t}}$ is the variance of the Bitcoin (BTC), $\beta_{\text {bcom }}{ }^{2} h_{\text {bcom }}$ is the part of the variance attributed to the systemic shocks transmitted by the Bloomberg Commodity Index (BCOM), and $\beta_{b m i_{t}}{ }^{2} h_{b m i_{t}}$ is the part of the variance attributed to the systemic shocks transmitted by the S\&P Global index (BMI). The term $2 \beta_{b c o m t} \beta_{b m i_{t}} h_{b c o m}, b m i_{t}$ accounts for the effect of the covariance between the two systemic factors on the variance of the Bitcoin (BTC), and $h_{\varepsilon_{t}}$ is the part of the variance attributed to idiosyncratic factors or unique risk. Therefore, it allows for the further decomposition of the variance of Bitcoin (BTC) into its systemic and idiosyncratic risk components using Equation 5:

$u_{s y s, b c_{t}}=\frac{\beta_{b c o m m_{t}} h_{b c o m m_{t}}+\beta_{b m i_{t}} h_{b m i_{t}}+2 \beta_{b c o m_{t}} \beta_{b m i_{t}} h_{b c o t_{t}, b m i_{t}}}{h_{b c_{t}}}$,

$u_{i d i o, b t t_{t}}=\frac{h_{\varepsilon_{t}}}{h_{b t c_{t}}}$.

The resulting time series for the percentage of BTC variance explained by systemic risk are obtained from Equation 5. With the resulting percentage time series, it is straightforward to test if there is a statistically significant difference between the average idiosyncratic risk between the pre-COVID-19 and post-COVID-19 periods using a t-test for the difference in means. There is also a structural time break series test for robustness purposes.

\section{RESULTS AND DISCUSSION}

The time series for the Bitcoin idiosyncratic risk in terms of percentage is obtained by applying the procedure described in Equations 1-5. The NBC news on COVID-19 timeline (2020) was used to identify the period when the pandemic started to take on momentum, which was when the World Health Organization (WHO) declared a global public health emergency after more than 9,000 deaths were confirmed on January 30, 2020. Therefore, the pre-COVID-19 period is between February 10, 2016, and January 29, 2020, and the post-COVID-19 period is between January 30, 2020, and March 2, 2021. The average idiosyncratic risk is calculated for each period, and the results are summarized in Table 2. From the table, one can observe that the distinction between the two averages is statistically significant and that the unique or idiosyncratic risk of the Bitcoin (BTC) return increases almost 900 basis points from the pre-COVID-19 period, showing that Bitcoin can act as a safe haven or hedge asset, at least from a portfolio composed of global stocks and commodities.

Table 2. $T$-test for distinctions in unique or idiosyncratic risk of Bitcoin for the pre-COVID-19 period and the post-COVID period

\begin{tabular}{l|c:c}
\hline \multicolumn{1}{c}{ Statistic } & Pre-COVID & Post-COVID \\
\hline Mean (BTC unique risk) & $86.06 \% * * *$ & $95.05 \% * * *$ \\
Variance & 0.00951 & 0.00417 \\
\hline Observations & 998 & 292 \\
\hline Group variance & 0.00883 & \\
\hline Hypothetical difference & 0 & \\
between means & 1288 & \\
\hline Degrees of freedom & -14.824 & \\
\hdashline$T$-Stat & $2.508 \mathrm{E}-29$ & \\
\hdashline$P(T<=t$ ) value one-tail & 1.646 & \\
\hdashline$T$-Stat critical value (one tail) & & \\
\hdashline$P(T<=t$ ) value two-tails & $5.015 \mathrm{E}-29$ & \\
\hline$T$-Stat critical value (two tails) & 1.961 & \\
\hline
\end{tabular}

Note: The table reports the average unique risk for the time series for each period obtained by applying the procedure described in Equations $1-5 . *, * *$, and $* * *$ mean confidence levels at 90\%, 95\%, and 99\%, respectively.

Figure 3 details the dynamic behavior of systemic risk explained by the interaction between the Bloomberg Commodity Index (BCOM) and the S\&P Global Broad Market Index (BMI). In 2020, on average, the risk generated from the systemic explanatory factors tends to dampen during the height of the COVID-19 pandemic.

In Figure 3 the effect during the first year of the pandemic is noticeable when compared with the behavior of systemic risk in previous periods. For 


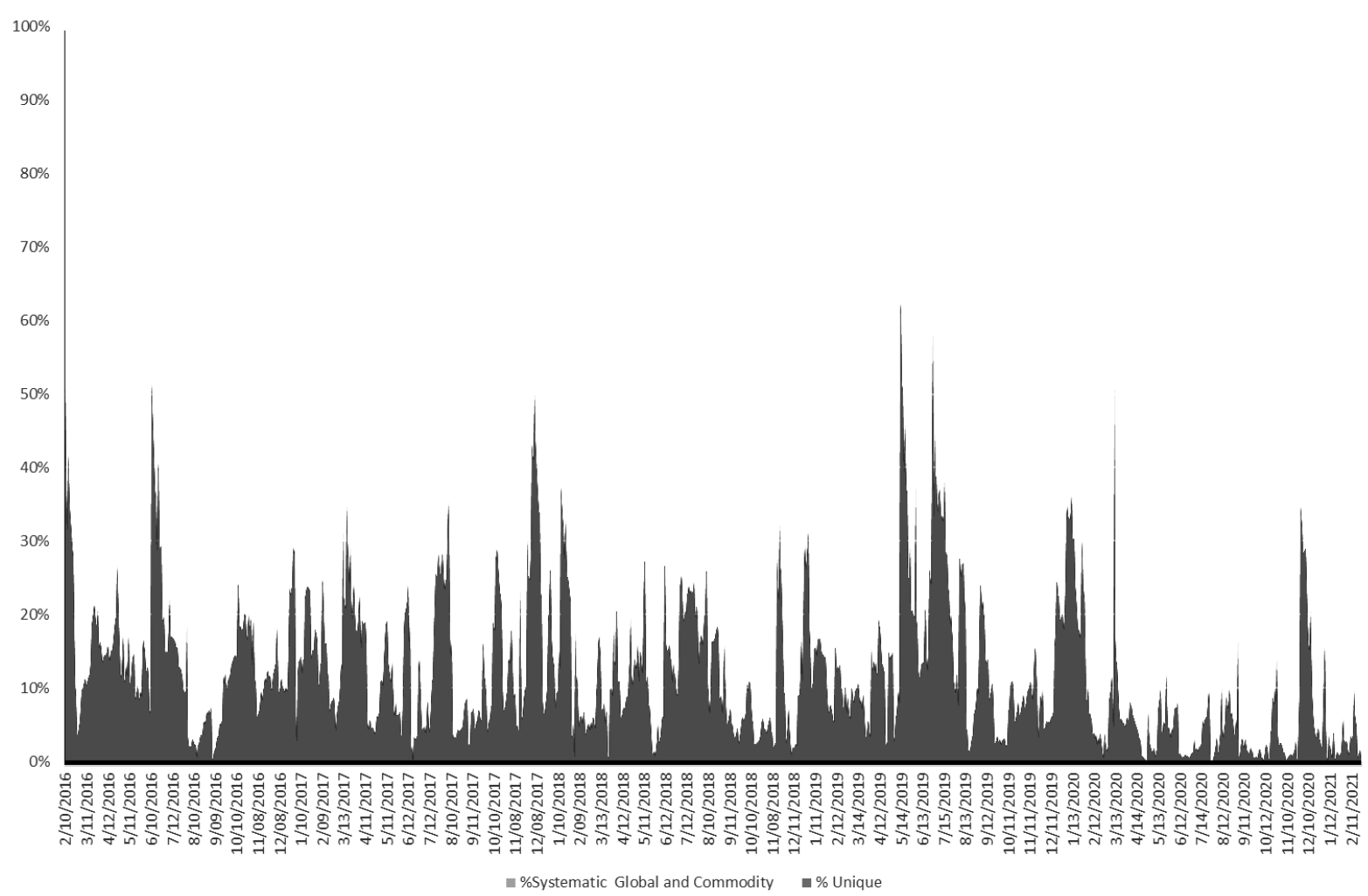

Note: The figure shows the proportion of conditional volatility for the returns in the Bitcoin (BTC) returns due to systemic volatility arising from shocks from commodities and global stock markets. The proportions are obtained using the estimates from Equations 1-5 and their respective time series for the period under scrutiny.

Figure 3. Conditional variance decomposition: Bitcoin returns from February 10, 2016 to March 2, 2021

example, the average idiosyncratic risk for Bitcoin for $2016,2017,2018$, and 2019 was $85.63 \%, 85.76 \%$, $88.38 \%$, and $85.43 \%$, respectively, and for 2020 and the fraction of 2021, the unique risk of Bitcoin was $92.97 \%$ and $96.86 \%$, respectively. In Table 3 , there are the monthly averages of the total systemic risk attributable to both the commodity and global stock factors, as well as the contribution of the covariance between those factors, to see the effect of their interdependence in the estimates for unique risk for the year before and the year after the pandemic.

From Table 3, and for all periods under observation, the covariance between the commodity index and the global stock markets is negative. This negative covariance tends to lower the effect of systemic risk. Before the pandemic, in October 2019 and December 2019, the commodity index acted as a greater contributor to systemic risk than the global stock index. It is interesting that, at the beginning of the pandemic, the portion of the total systemic risk attributable to the factors was higher than before the pandemic. However, as the pandemic evolved during the year, the contribution of the factors to systemic risk dampened rapidly. This means that, in a portfolio composed of commodities, global stocks, and Bitcoin, the latter can act as a safe haven asset in times of exogenous systemic shocks (such as the pandemic), since common sources of systemic shock, such as the global stock and commodities markets, become insignificant sources of systemic risk transmission in times of uncertainty due to a global exogenous systemic shock (namely, the COVID-19 pandemic). To test the robustness of the $t$-test for differences in mean for the pre-COVID-19 and post-COVID-19 periods, there was an alternative structural break test for the date in which the sample was divided into two (Table 4).

From Table 4, the structural break test rejects the null hypothesis that each subsample is not statistically different; therefore, the choice of date for dividing the data in the sample contributed to explaining the differences in means. 
Table 3. Monthly average of unique and systemic risk of the Bitcoin attributable to shocks from the Bloomberg Commodity Index and the S\&P Global Broad Market Index

\begin{tabular}{|c|c|c|c|c|c|}
\hline Period & $\begin{array}{c}\text { Total } \\
\text { idiosyncratic } \\
\text { or unique risk } \\
\text { attributable } \\
\text { to the Bitcoin } \\
\text { (BTC) } \\
\end{array}$ & $\begin{array}{c}\text { Total systemic risk } \\
\text { attributable to the } \\
\text { Bloomberg Commodity } \\
\text { Index (BCOM) and the } \\
\text { S\&P Global Broad Market } \\
\text { Index (BMI) }\end{array}$ & $\begin{array}{l}\text { Contribution } \\
\text { of the Bloomberg } \\
\text { Commodity } \\
\text { Index (BCOM) } \\
\text { to systemic risk }\end{array}$ & $\begin{array}{c}\text { Contribution } \\
\text { of the S\&P Broad } \\
\text { Market Index } \\
\text { (BMI) to systemic } \\
\text { risk }\end{array}$ & $\begin{array}{l}\text { Contribution } \\
\text { of the covariance } \\
\text { between the } \\
\text { BCOM and BMI } \\
\text { to systemic risk }\end{array}$ \\
\hline January 2019 & $84.31 \%$ & $15.69 \%$ & $8.17 \%$ & $16.24 \%$ & $-8.72 \%$ \\
\hline February 2019 & $90.39 \%$ & $9.61 \%$ & $4.57 \%$ & $11.82 \%$ & $-6.78 \%$ \\
\hline March 2019 & $92.13 \%$ & $7.87 \%$ & $4.49 \%$ & $11.12 \%$ & $-7.73 \%$ \\
\hline April 2019 & $88.43 \%$ & $11.57 \%$ & $6.26 \%$ & $18.20 \%$ & $-12.90 \%$ \\
\hline May 2019 & $73.36 \%$ & $26.64 \%$ & $5.06 \%$ & $32.35 \%$ & $-10.77 \%$ \\
\hline June 2019 & $78.52 \%$ & $21.48 \%$ & $9.04 \%$ & $31.21 \%$ & $-18.78 \%$ \\
\hline July 2019 & $71.22 \%$ & $28.78 \%$ & $19.43 \%$ & $48.74 \%$ & $-39.39 \%$ \\
\hline August 2019 & $87.83 \%$ & $12.17 \%$ & $5.22 \%$ & $13.98 \%$ & $-7.03 \%$ \\
\hline September 2019 & $87.61 \%$ & $12.39 \%$ & $17.07 \%$ & $19.68 \%$ & $-24.36 \%$ \\
\hline October 2019 & $94.25 \%$ & $5.75 \%$ & $6.97 \%$ & $5.19 \%$ & $-6.41 \%$ \\
\hline November 2019 & $90.77 \%$ & $9.23 \%$ & $12.29 \%$ & $12.43 \%$ & $-15.48 \%$ \\
\hline December 2019 & $87.17 \%$ & $12.83 \%$ & $17.93 \%$ & $12.82 \%$ & $-17.92 \%$ \\
\hline January 2020 & $73.31 \%$ & $26.69 \%$ & $20.83 \%$ & $41.85 \%$ & $-35.99 \%$ \\
\hline February 2020 & $95.39 \%$ & $4.61 \%$ & $3.75 \%$ & $4.65 \%$ & $-3.80 \%$ \\
\hline March 2020 & $90.75 \%$ & $9.25 \%$ & $3.12 \%$ & $7.43 \%$ & $-1.30 \%$ \\
\hline April 2020 & $96.00 \%$ & $4.00 \%$ & $4.11 \%$ & $0.95 \%$ & $-1.06 \%$ \\
\hline May 2020 & $95.60 \%$ & $4.40 \%$ & $0.45 \%$ & $4.71 \%$ & $-0.76 \%$ \\
\hline June 2020 & $97.23 \%$ & $2.77 \%$ & $1.34 \%$ & $2.66 \%$ & $-1.24 \%$ \\
\hline July 2020 & $96.78 \%$ & $3.22 \%$ & $2.50 \%$ & $3.14 \%$ & $-2.42 \%$ \\
\hline August 2020 & $94.83 \%$ & $5.17 \%$ & $1.67 \%$ & $7.69 \%$ & $-4.19 \%$ \\
\hline September 2020 & $97.27 \%$ & $2.73 \%$ & $1.46 \%$ & $3.04 \%$ & $-1.77 \%$ \\
\hline October 2020 & $96.43 \%$ & $3.57 \%$ & $1.23 \%$ & $4.96 \%$ & $-2.62 \%$ \\
\hline November 2020 & $98.38 \%$ & $1.62 \%$ & $0.95 \%$ & $1.72 \%$ & $-1.05 \%$ \\
\hline December 2020 & $84.30 \%$ & $15.70 \%$ & $9.19 \%$ & $20.63 \%$ & $-14.12 \%$ \\
\hline
\end{tabular}

Note: The average percentages of total systemic risk as a proportion of systemic risk and the respective contributions of each factor to systemic risk are corrected by their covariance are obtained using the estimates from Equations 1-5.

Table 4. Breusch-Godfrey Lagrange multiplier tests for serial correlation

\begin{tabular}{|c|c|}
\hline Null hypothesis: & $\begin{array}{l}\text { There is no structural break for the time series of Bitcoin (BTC) due to the COVID-19 } \\
\text { pandemic after January 31,2019. }\end{array}$ \\
\hline Alternative hypothesis: & $\begin{array}{l}\text { There is a structural break for the time series of the Bitcoin (BTC) due to the COVID-19 } \\
\text { pandemic after January } 31,2019 .\end{array}$ \\
\hline Structural Break Test Point Period & 998 \\
\hline Total Sums of Squares of Residuals & 12.369 \\
\hline First Subset Sums of Squares of Residuals & 9.07 \\
\hline Second Subset Sums of Squares of Residuals & 2.152 \\
\hline Computed Test Statistic & $129.642 * * *$ \\
\hline$P$-value & 0.000 \\
\hline
\end{tabular}

Note: This table summarizes the results obtained from running a structural break test for the date mentioned in the hypothesis for the time series of unique risk obtained using the procedure from Equations 1-5.

\section{CONCLUSION}

This paper examines the interaction between sources of market systemic shocks and their effect on the variance of Bitcoin when exposed to a global exogenous systemic shock such as the COVID-19. The pandemic offers a unique opportunity to test the properties of Bitcoin as a safe haven asset. In the proposed framework, the Bloomberg Commodity Index (BCOM) and the S\&P Global Market Index (BMI) as 
possible sources of market systemic shock transmission to test their effect on the unique risk of Bitcoin (BTC) before and during the ongoing COVID-19 pandemic.

The results show that for the first year of the pandemic, the unique risk or idiosyncratic risk of Bitcoin (BTC) rose significantly compared to the pre-COVID period. A statistically significant increase in idiosyncratic is a desirable characteristic of safe haven assets in a time of economic crisis. The results demonstrate that Bitcoin (BTC) indeed exhibits characteristics that are expected from safe haven or hedge assets during periods of increased global systemic risk due to exogenous shocks. Finally, it is important to highlight that the contribution of variance to the Bitcoin (BTC) from systemic risk sources such as global equities and commodities during the period of the study exhibited a time-variant behavior. In other words, during the period previous to the pandemic, commodities were a major source of systemic risk to the Bitcoin (BTC) as compared to global equities; however, during the pandemic global equities became the major source of systemic risk.

\section{AUTHOR CONTRIBUTIONS}

Conceptualization: Edgardo Cayón Fallon, Julio Sarmiento.

Data curation: Edgardo Cayón Fallon, Julio Sarmiento.

Formal analysis: Edgardo Cayón Fallon.

Investigation: Edgardo Cayón Fallon, Julio Sarmiento.

Methodology: Edgardo Cayón Fallon, Julio Sarmiento.

Software: Edgardo Cayón Fallon, Julio Sarmiento.

Validation: Edgardo Cayón Fallon, Julio Sarmiento.

Writing - original draft: Edgardo Cayón Fallon, Julio Sarmiento.

Writing - review \& editing: Edgardo Cayón Fallon, Julio Sarmiento.

\section{REFERENCES}

1. Ahelegbey, D. F., Giudici, P., \& Mojtahedi, F. (2021). Tail risk measurement in crypto-asset markets. International Review of Financial Analysis, 73, 101604 http://dx.doi.org/10.1016/j. irfa.2020.101604

2. Akhtaruzzaman, M., Boubaker, S., \& Sensoy, A. (2021). Financial contagion during COVID-19 crisis. Finance Research Letters, 38, 101604. https://doi.org/10.1016/j. frl.2020.101604

3. Akhtaruzzaman, M., Sensoy, A., \& Corbet, S. (2020). The influence of bitcoin on portfolio diversification and design. Finance Research Letters, 37, 101344. Retrieved from https://papers.ssrn.com/sol3/papers.cfm?abstract_id $=3758512$

4. Bakry, W., Rashid, A., Al-Mohamad, S., \& El-Kanj, N. (2021). Bitcoin and Portfolio Diversification: A Portfolio Optimization Approach. Journal of Risk and Financial Management, 14(7),
282. https://doi.org/10.3390/ jrfm14070282

5. Baldan, C., \& Zen, F. (2020). The Bitcoin as a Virtual Commodity: Empirical Evidence and Implications. Frontiers in Artificial Intelligence, 3. https://doi.org/10.3389/ frai.2020.00021

6. Baur, D. G., \& Lucey, B. M. (2010). Is gold a hedge or a safe haven? An analysis of stocks, bonds and gold. Financial Review, 45(2), 217-229. https://doi.org/10.1111/ j.1540-6288.2010.00244.x

7. Belhassine, O., \& Karamti, C. (2021). Contagion and portfolio management in times of COVID-19. Economic Analysis and Policy, 72, 73-86. https://doi. org/10.1016/j.eap.2021.07.010

8. Bouri, E., Molnár, P., Azzi, G., Roubaud, D., \& Hagfors, L. I. (2017). On the hedge and safe haven properties of Bitcoin: Is it really more than a diversi- fier? Finance Research Letters, 20, 192-198. https://doi.org/10.1016/j. frl.2016.09.025

9. Caporale, G. M., Kang, W.-Y., Spagnolo, F., \& Spagnolo, N. (2021). Cyber-attacks, spillovers and contagion in the cryptocurrency markets. Journal of International Financial Markets, Institutions and Money, 74, 101298. https://doi. org/10.1016/j.intfin.2021.101298

10. Carpenter, A. (2016). Portfolio diversification with Bitcoin. Journal of Undergraduate Research in Finance, 6(1), 1-27. Retrieved from https://jurf.org/wp-content/ uploads/2017/01/carpenter-andrew-2016.pdf

11. Cayon, E., \& Sarmiento, J. (2020). Testing for contagion from oil and developed markets to emerging markets: An empirical analysis using systemic risk parameter. Journal of International Studies, 13(2). https://doi.org/10.14254/20718330.2020/13-2/7 
12. Cayon, E., \& Thorp, S. (2014). Financial Autarchy as Contagion Prevention: The Case of Colombian Pension Funds. Emerging Markets Finance and Trade, 50(sup3), 122-139. https://doi.org/10.2753/ REE1540-496X5003S307

13. Chen, Y., Giudici, P., Misheva, B. H., \& Trimborn, S. (2020). Lead behaviour in bitcoin markets. Risks, 8(1), 4. https://doi.org/10.3390/ risks 8010004

14. CoinMarketCap. (n.d.). Today's Cryptocurrency Prices by Market Cap. Retrieved September 30, 2021, from https://coinmarketcap.com/

15. Danylyshyn, B. (2020). The peculiarities of economic crisis due to COVID-19 pandemic in a developing country: case of Ukraine. Problems and Perspectives in Management, 18(2), 13-22. http://dx.doi.org/10.21511/ ppm.18(2).2020.02

16. Dyhrberg, A. H. (2016). Bitcoin, gold and the dollar - A GARCH volatility analysis. Finance Research Letters, 16(C), 85-92. https://doi. org/10.1016/j.frl.2015.10.008

17. Eisl, A., Gasser, S. M., \& Weinmayer, K. (2015). Caveat Emptor: Does Bitcoin Improve Portfolio Diversification? SSRN Electronic Journal. https://doi.org/10.2139/ ssrn.2408997

18. Erdas, M. L., \& Caglar, A. E. (2018). Analysis of the relationships between Bitcoin and exchange rate, commodities and global indexes by asymmetric causality test. Eastern Journal of European Studies, 9(2), 27-45. Retrieved from https://econpapers.repec.org/article/jesjournl/ y_3a2018_3av_3a9_3ap_3a27-45. htm

19. Ferreira, P., \& Pereira, É. (2019). Contagion effect in cryptocurrency market. Journal of Risk and Financial Management, 12(3), 1-8. Retrieved from https://ideas. repec.org/a/gam/jjrfmx/v12y2019i3p115-d247119.html

20. Ghorbel, A., \& Jeribi, A. (2021a). Contagion of COVID-19 pandemic between oil and financial assets: the evidence of multivariate Markov switching GARCH mod- els. Journal of Investment Compliance, 22(2), 151-169. https://doi. org/10.1108/JOIC-01-2021-0001

21. Ghorbel, A., \& Jeribi, A. (2021b). Volatility spillovers and contagion between energy sector and financial assets during COVID-19 crisis period. Eurasian Economic Review, 11, 449-467. https://dx.doi.org/10.1 007\%2Fs40822-021-00181-6

22. Graf, K. S. (2014). Commodity, scarcity, and monetary value theory in light of bitcoin. Prices \& Markets, 3(3), 1-24.

23. Guegan, D., \& Frunza, M.C. (2020). Bubbles on bitcoin price: The bitcoin rush. In Risk Factors and Contagion in Commodity Markets and Stocks Markets (pp. 1-24). http://dx.doi. org/10.1142/9789811210242_0001

24. Hayes, A. S. (2019). Bitcoin price and its marginal cost of production: support for a fundamental value. Applied Economics Letters, 26(7), 554-560. https://doi.org/10.1 080/13504851.2018.1488040

25. Hoang, K., Nguyen, C. C., Poch, K., \& Nguyen, T. X. (2020). Does Bitcoin Hedge Commodity Uncertainty? Journal of Risk and Financial Management, 13(6), 119. https://doi.org/10.3390/ jrfm13060119

26. Matkovskyy, R., \& Jalan, A. (2019). From financial markets to Bitcoin markets: A fresh look at the contagion effect. Finance Research Letters, 31, 93-97. http://dx.doi. org/10.1016/j.frl.2019.04.007

27. Ozili, P. K., \& Arun, T. (2020). Spillover of COVID-19: impact on the Global Economy. SSRN Electronic Journal. Retrieved from https://papers.ssrn.com/sol3/papers.cfm?abstract_id $=3562570$

28. Ozturk, M., \& Cavdar, S. C. (2021). The Contagion of Covid-19 Pandemic on The Volatilities of International Crude Oil Prices, Gold, Exchange Rates and Bitcoin. The Journal of Asian Finance, Economics and Business, 8(3), 171-179. https://doi.org/10.13106/ jafeb.2021.vol8.no3.0171

29. Phuong, L. C. M. (2021). How COVID-19 impacts Vietnam's bank- ing stocks: An event study method. Banks and Bank Systems, 16(1), 92-102. http://dx.doi.org/10.21511/ bbs.16(1).2021.09

30. Qarni, M. O., \& Gulzar, S. (2021). Portfolio diversification benefits of alternative currency investment in Bitcoin and foreign exchange markets. Financial Innovation, 7(1), 1-37. http://dx.doi.org/10.1186/ s40854-021-00233-5

31. Salisu, A. A., Isah, K., \& Akanni, L. O. (2019). Improving the predictability of stock returns with Bitcoin prices. The North American Journal of Economics and Finance, 48, 857-867. https://doi.org/10.1016/j. najef.2018.08.010

32. Sansa, N. A. (2020). The Impact of the COVID-19 on the Financial Markets: Evidence from China and USA. Electronic Research Journal of Social Sciences and Humanities, 2(2). http://dx.doi.org/10.2139/ ssrn.3567901

33. Schwenkler, G., \& Zheng, $\mathrm{H}$. (2020). Competition or contagion? Evidence from cryptocurrency peers (Santa Clara University working paper).

34. Shahzad, S. J. H., Bouri, E., Roubaud, D., Kristoufek, L., \& Lucey, B. (2019). Is Bitcoin a better safehaven investment than gold and commodities? International Review of Financial Analysis, 63, 322330. http://dx.doi.org/10.1016/j. irfa.2019.01.002

35. Tsiaras, K. (2021). Financial Contagion and Volatility Spillover: an exploration into Bitcoin Future and FOREX Future Markets. Journal of Economics, 6(1). https://doi. org/10.46763/JOE216.1001t

36. Wang, H., Wang, X., Yin, S., \& Ji, H. (2021). The asymmetric contagion effect between stock market and cryptocurrency market. Finance Research Letters, 102345. https:// doi.org/10.1016/j.frl.2021.102345

37. Zhang, Y. J., Bouri, E., Gupta, R., \& Ma, S. J. (2021). Risk spillover between Bitcoin and conventional financial markets: An expectilebased approach. The North American Journal of Economics and Finance, 55, 101296. https://doi. org/10.1016/j.najef.2020.101296 